\title{
Revisão da Literatura Acerca da Assistência de Enfermagem ao Parto Humanizado
}

\author{
Couto, Camila Santos do; Rocha, Ana Fátima Braga; Araújo, Cláudia Mota; Bezerra, \\ Maria Socorro Ferreira; Paiva, Pâmela Campelo; Oliveira, Christina Costa de \\ Universidade de Fortaleza — cmlcouto@gmail.com
}

Introdução: a humanização tem como foco a qualificação da atenção, envolvendo tanto o respeito e a promoção dos direitos humanos, quanto a formação de profissionais que implantem práticas baseadas nas evidências científicas, os ambientes com instalações adequadas e os recursos tecnológicos disponíveis. Nessa concepção, percebe-se a suma importância dos profissionais de saúde no processo da humanização do parto e nascimento e da assistência em geral. Objetivos: Revisar a literatura científica nacional publicada acerca das barreiras e estratégias relacionadas à assistência de enfermagem ao parto humanizado. Métodos: Trata-se de um estudo de revisão bibliográfica. a busca pela literatura foi realizada na base de dados Literatura Latino-Americana em Ciências de Saúde nos meses de setembro e outubro de 2012. Os descritores foram selecionados a partir da terminologia em saúde consultada nos Descritores em Ciências da Saúde (DECS), sendo eles: "parto humanizado" e "enfermagem". Foram incluídos apenas estudos completos dos últimos seis anos, disponíveis eletronicamente, de produção nacional, com temática pertinente ao trabalho. Após a análise e leitura dos artigos, a amostra final apresentou 09 publicações. Resultados: a partir da análise dos artigos, emergiram duas categorias: Barreiras na assistência de enfermagem ao parto humanizado e Estratégias relacionadas à assistência ao parto humanizado. Barreiras na assistência de enfermagem ao parto humanizado: Fatores como a dificuldade de acesso dos profissionais ao conhecimento, o uso indiscriminado de intervenções; as elevadas taxas de cesáreas e a impossibilidade em alguns sérvios de saúde da presença do acompanhante no Centro Obstétrico são apontados na amostra da pesquisa como barreiras relacionadas à assistência humanizada. Estratégias relacionadas à assistência ao parto humanizado: Dentre as estratégias observadas nos artigos, as mais pontuadas foram: a disponibilidade do profissional dispondo seu saber; o estimulo a formação de profissionais sensíveis e aptos a compreender a dimensão humana do cuidado e participar ativamente nas transformações do cuidado materno e perinatal; incentivo ao processo de educação continuada e da formação de profissionais em saúde voltados para o resgate do respeito à vida humana. Conclusão: de acordo com o objetivo do estudo, conclui-se que as produções bibliográficas caracterizam diversas barreiras e estratégias no tocante da promoção da humanização da assistência ao parto. Os profissionais devem aguçar a sensibilidade mediante a assistência prestada, tendo a consciência e o respeito de que a gestante se encontra num determinado estado de ambivalência. Este estudo traz a possibilidade de repensar modelos e práticas de saúde à mulher em sua totalidade como ser humano, sem negar a sua subjetividade.

Couto, Camila Santos do; Rocha, Ana Fátima Braga; Araújo, Cláudia Mota; Bezerra, Maria Socorro Ferreira; Paiva, Pâmela Campelo; Oliveira, Christina Costa de. Revisão da Literatura Acerca da Assistência de Enfermagem ao Parto Humanizado. In: Anais do Congresso Internacional de Humanidades \& Humanização em Saúde [= Blucher Medical Proceedings, num.2, vol.1]. São Paulo: Editora Blucher, 2014. ISSN 2357-7282

DOI 10.5151/medpro-cihhs-10424 